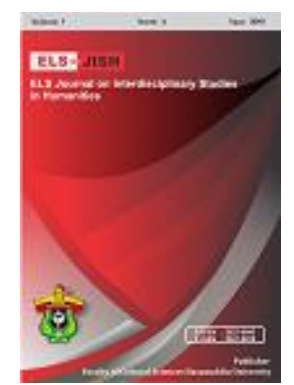

\title{
ELS-JISH
}

ELS Journal on Interdisciplinary Studies on Humanities

Volume 2 Issue 3, 2019

ISSN (print) : 2621-0843

ISSN (online) : 2621-0835

Homepage : http://journal.unhas.ac.id/index.php/jish

\section{Features of Disfluent speech by EFL Learners at Taiz University}

\author{
Abeer Algazali ${ }^{1}$ \\ 1 algazaliabeer@gmail.com
}

\begin{abstract}
This paper aims at investigating the features of disfluent speech by EFL learners at Taiz University. Disfluent speech features usually lead to listeners' negative impressions on the EFL learners' speech. This paper focuses on repair fluency aspects as fillers, repetitions, restarts and reformulations. Analysing those features contributes to the understanding of the ongoing learner's needs that should be put into concentration during teaching. The data was collected from 20 level four students of English Language major, Faculty of Education, Taiz University. The participants were asked to narrate the events of a short silent video. The quantitative analysis showed that the participants overused disfluencies such as fillers, prolongations, repetitions, restarts and self-corrections. The mostly present self corrected item was the pronouns. This paper recommends that in order for the EFL learners to make their speech sound more fluent and more natural, they should be firstly introduced to the notion of disfluent speech features, and then they should be trained using some activities that focus on fostering fluency.
\end{abstract}

Keywords: Disfluent speech, disfluency features, fluency

How to cite: Algazali, A. (2019). Features of Disfluent speech by EFL Learners at Taiz University. ELS Journal on Interdisciplinary Studies in Humanities, 2 (3), 398-409

\section{Introduction}

Accuracy and fluency are two important aspects of using a language either in speaking or in writing, though the term fluency is mostly attached to speaking more than to other language skills (Al-Ghazali \& Alrefaee, 2019). According to Alanisi (2012) accuracy refers to how correct learners' use of the language system is, including their use of grammar, pronunciation and vocabulary. Fluency, on the other hand, refers to "how well learners communicate meaning rather than how many mistakes they make in grammar, pronunciation and vocabulary" (Alanisi, 2012, p. 56). Accuracy refers to the correct use of language in terms of grammar, vocabulary and pronunciation. According to Nunan (2003, p.10) "Fluency is the extent to which speakers use the target language quickly and confidently with few hesitations or unnatural pauses, false starts, word searches".

At the Department of English Language, Faculty of Education, Taiz University, there are four courses that focus mainly on the speaking skill, namely; Spoken I, Spoken II, Spoken III and Spoken IV, distributed over the first two years of the

${ }^{1,}$ Taiz University, Yameen 
program. Moreover, the overall aims of these subjects as specified in the course description are respectively: "to build confidence among the learners to speak English and get over their tongue tidiness while using English, to help students participate in conversations, to help the learners negotiate through language, and to help individual learners to make presentations and also participate in debates, recitations, and declamations and also take part in plays and skits", (Mohanraj, 2006, p. 6). However, there is a gap between what is prescribed for the EFL learners and the product of those courses in reality. This is confirmed by Alanisi (2012) who analysed the teaching methods, the syllabuses, and the textbooks used in teaching the speaking skill at colleges of Education in Yemeni universities. As stated by Alanisi (2012, p. 175) "there is no correspondence, to a great extent, between the aims stated by the syllabus and the topics in the texts used in teaching speaking. The tasks/ activities do not encourage interaction and do not give space to learners to express themselves because they are required to model their speech after given examples or limit themselves to answering a set of questions".

Speaking fluency, as defined by Bulc et al. (2010), is "speech at a natural rate without many hesitations, pauses, repetitions, reformulations, filler words and filled or unfilled pauses" (p. 88). This study investigates the disfluency features as hesitations, repetitions, false starts and pausing which are of a great importance with respect to listeners' negative impressions on the EFL learners' speech. This is pointed out by Hemerka (2009, p. 15) who states that "People who often have to search for words, make a lot of pauses, slips and false starts, frequently use fillers often go for inappropriate words and awkward constructions, can hardly earn being labelled skilful speakers". In addition, it is emphasized by Bosker (2014, p. 1) that "disfluent non-native speech negatively affects the impression that listeners have of the non-native speaker". This study would also provide data that are likely to be reconsidered with regards to text book writers, teachers of English and language researchers. According to Alyan (2013), "pronunciation is seen as an obstacle that can hinder learners' fluency". That is, the findings of this study are hoped to encourage the EFL learners to use language freely even if they make mistakes either in grammar or in pronunciation. Therefore, this study is expected to help EFL learners pass their message across without preoccupation on being grammatical.

\section{Literature Review}

Disfluency, sometimes spelled as 'Dysfluency', refers to "a breakdown in normal speech while pausing" (Richards and Schmidt 2002, p. 215). Gósy (2007, p. 93) defines speech disfluencies as "phenomena that interrupt the flow of speech and do not add propositional content to an utterance". Disfluency includes false starts, hesitations, repetitions and fillers. Disfluency features, which are carried out by various means as repetition, reformulation and false starts, do not necessarily mean there is an error in the speech. They can be taken as one of the forms of disfluency when the speaker hesitates because he or she needs more time for further planning of speech and speaking. Some studies show that repair fluency features, especially hesitations, might help the listener to focus his/her attention to the message produced by the speaker. A study by Bosker (2014) investigated the listeners' attention to a target word produced in both fluent and disfluent native speech utterance. It was found that disfluent utterance had a beneficial effect on the listener participants' recall of the target word. That is, the listeners were more likely to recall 
the word produced in a disfluent utterance than the word in fluent context. Surprisingly enough, the same was not true when the listeners had non-native speakers' utterances. This means that, at times, native speakers draw the attention of the listener by producing a hesitation, as um, before the target word but non-native speakers make use of hesitations to recall a word or to win time of speech. According to Bosker (2014), the native speakers use hesitation for a purpose, and it, therefore, does not hinder communication. For the non-native speakers, Kormos (2006) assumed that repetitions, reformulations, and restarts which often accompany silent or filled pauses are signs of encoding difficulties during the speech production process. A filled pause is a pause that contains a filler such as 'um', 'ah', 'er' or the like of those, which are also called hesitations (Kormos and Denes, 2004).

False starts are the utterances by the speaker which are discarded, and then the speaker starts another utterance, Riggenbach (1991). Hesitations are the use of ahs ums or ers as a technique for word or structure remembering. Repetitions refer to repeating a phrase, a word or a part of a word while speaking. Fillers are words that add no meaning to the speech but said as to fill time with speech or recall ideas, words and structures. Fillers as "ah" "um" and "er" are regarded as hesitation markers. There are also filler phrases as "you see" and "you know" which are typical native speaker fillers.

Alanisi (2012) investigated the factors that affect speaking proficiency of Yemeni student-teachers in speaking English in three colleges of Education; College of Education-Thamar, College of Education- Rada'a and College of EducationAlBaida. He analysed the teaching methods, the syllabuses, and the textbooks used in teaching the speaking skill at those colleges. Data were collected through classroom observation, interviews with student-teachers, and interviews with teachers. He found out significant results that establish the causes of the low level of speaking proficiency amongst the Yemeni student-teachers. Those factors were the teaching methods and the materials used in teaching the Spoken courses. Alanisi found out that the speaking skill is not adequately dealt with both at school level and at college level. Alanisi adds that "speaking is a neglected skill in teaching as well as in testing. The learners do not have adequate opportunities to use the language even in the classroom due to the traditional methods used in teaching speaking by the Yemeni teachers. Most of the learners do not have intrinsic motivation to speak the language and they study English only for a short term goal" (p.171). What is of great concern is Alanisi's remark that in the investigated colleges, the emphasis is given to accuracy rather than to fluency and that "the learners are scared of committing mistakes at which the teachers might laugh. They are also afraid of being subjects to the teachers' negative feedback" (p. 172).

The previously mentioned studies on the temporal features of speaking fluency were done in the EFL teaching-Learning contexts other than the Yemeni context. The studies done in the Yemeni EFL context were not focused on the temporal aspect of speaking fluency. Thus, the researcher hardly found any studies on this aspect of fluency, disfluent speech features, in Yemen. Therefore, this study is hoped to present a clear and steady description of learners' strengths and weaknesses among the temporal components of repair fluency. 


\section{Methodology}

\subsection{The population and sample of the study}

The population of the present study was all the Level Four students at the Department of English Language, Faculty of Education, Taiz University in the second semester of the academic year 2014/2015. The total number of the fourth level students was (86) learners, (7) male and (79) female. The sample of this study were 20 participants chosen systematically from the fourth level of the EFL learners at the Department of English Language, Faculty of Education, Taiz University. The gender factor was not taken into account; because the male learners are very few in comparison with the female ones as mentioned above. Only one male student was present in the systematically selected sample.

\subsection{The Speaking Task}

Previous researches on speaking fluency usually gather the data using a speech elicitation task. The speech elicitation tasks in the literature are of three categories as classified by Segalowitz (2010). The first category is a reading task in which the participants read a text. The second category is picture description task in which the participants are asked to make a story based on a sequence of photos without words or on silent films. The third category is a story retelling task in which the participants read or listen to a story first and then retell it. The best task type that matches the present study is the second task, the making of a story based on a silent film or on a sequence of pictures. In this study, the participants had made a story based on narrating the events of a short video they watched.

The researcher selected a silent video that contained successive events that are easy to be talked about. The story of the video is of two people, a man and a woman, waiting for the train sitting on a bench. A thief comes out of a sudden and steals the lady's bag. The man who is sitting next to her runs after the thief and brings the bag back to the lady. She feels happy and gives him a big hug. The man gets surprised at the hug. Then the train comes, and the lady gets on while the man happily waves 'Goodbye' to her. However, in the train, the lady smiles and checks a wallet in her hand. She finds money in it because when she hugged the man she actually stole his wallet from his bag. As the topic of the video is easy to grasp and has an unexpected end, all the participants were able to talk naturally about it.

\subsection{Procedures}

After the participants had watched the video, they went into the recording room and were given a paper that contained the same story of the video in consequent pictures so as not to lose the events (see Appendix A). Secondly, an excerpt of two minutes was taken from the speech of each subject. The samples were transcribed manually and features of disfluent speech were detected carefully. An example is given in Appendix (2).

\section{Results}

This paper investigates the nature of the disfluencies. Nature here refers to the type of disfluencies, their frequency and their place. It is important to note that filled pauses are regarded as part of the disfluencies. Other disfluencies include repetitions, restarts and self-corrections. For Chon, Sawyer and Ambrose (2007), 
disfluency includes interjections, abandoned utterances, repetitions of phrases, words or syllables, and sound prolongations. When transcribing the collected speeches, the researcher put all kinds of the disfluencies between square brackets. The number of disfluencies for each speaker is shown below in Figure 1.

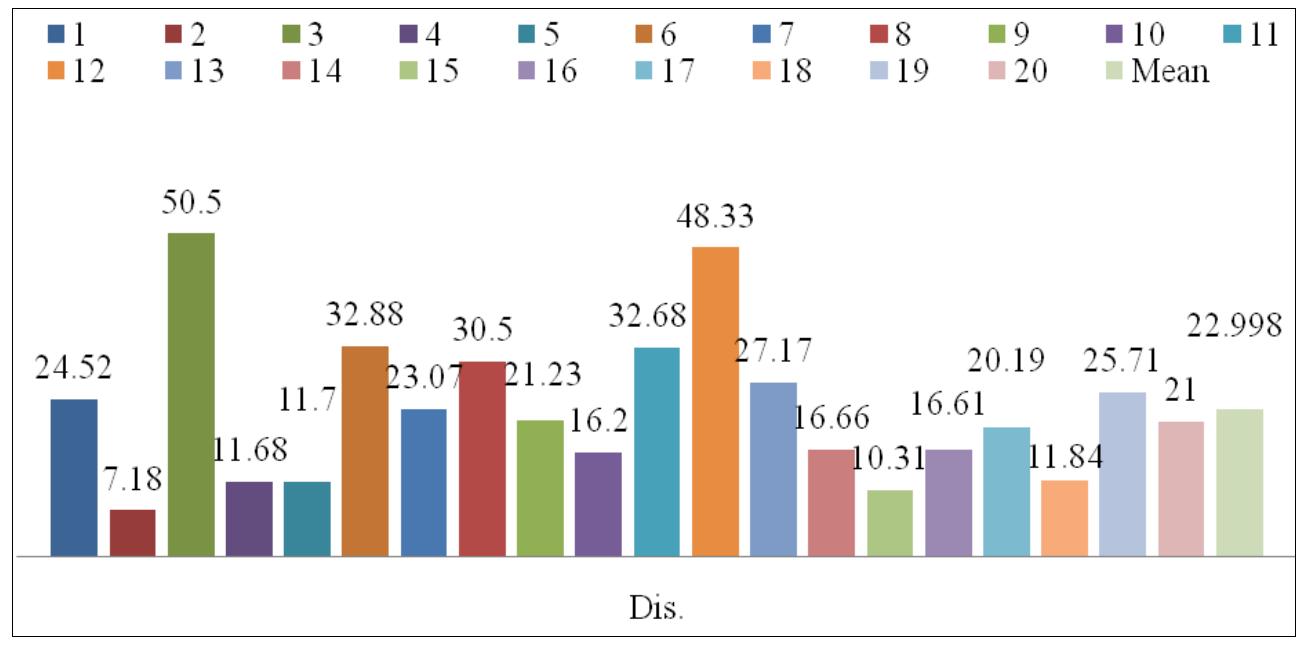

Figure 1. The Participants' Number of Disfluencies

\subsection{Number of disfluencies per minute}

An important variable of measuring speaking fluency as suggested by Kormos and Denes (2004) is the number of disfluencies per minute. In the transcribed speeches, disfluencies were marked if an utterance contained repetitions, (e.g., ride the [the] metro), restarts (e.g., [shee] (542) [we find]), fillers (ah, um, er), or selfcorrections (e.g., She gave it ah [he gave it]). The EFL learners at Taiz University uttered an average number of 22.99 (approximately 23 ) disfluencies per minute. That is to say, in a minutes of speech, $38.31 \%$ of the speech was merely disfluencies. That is, more than half a minute contains disfluencies. This is a relatively high frequency of using disfluencies by the EFL learners at Taiz University in comparison to the advanced learners of Kormos and Denes' (2004) study who used only 4.51 disfluencies per minute. Lennon (1990) suggests that learners who make a large proportion of disfluencies in their speech are likely to be considered as less fluent than those who produce few disfluencies despite the presence of disfluencies in both native and non-native speech. With respect to disfluencies, a distinction is made between the fluent and non-fluent use of disfluencies. Schmidt (1992, p. 377) says that 'Non-fluent learners' pauses, false starts, and other signs of hesitation reflect the need to focus attention on the lower levels of planning, whereas fluent learners act more like native speakers in exhibiting hesitation primarily as a reflection of integration and macroplanning". By lower levels of planning, Schmidt referred to planning for the grammatical structures of the sentences and by macroplanning, he referred to planning the ideas. This is also confirmed by Mirzaei and Heidari (2013) who say that the fluent L2 speakers utilize processing time pressure mechanisms, especially umming and erring, fillers, and other-repetition, more regularly than the non-fluent ones. According to Mirzaei and Heidari, "using this type of strategy, the fluent L2 speakers show that they are attempting to continue the conversation and bridge a communication gap while deficiencies in one's own language output, which might be revealed after encoding the message, lead to self-initiation, self-correction, or self-repair" (p. 51). 
The number of each disfluency type for each speaker who participated in this study is presented in Table 4 below.

Table 1. Types of Disfluencies

\begin{tabular}{lllll}
\hline Speaker & Repetitions & Restart & Corrections & $\begin{array}{l}\text { Hesitations } \\
\text { (fillers) }\end{array}$ \\
\hline S3 & 25 & 5 & 9 & 65 \\
\hline$S 4$ & 6 & 2 & 4 & 10 \\
\hline$S 5$ & 3 & 4 & 9 & 7 \\
\hline$S 6$ & 18 & 2 & 6 & 31 \\
\hline$S 7$ & 3 & 3 & 6 & 18 \\
\hline$S 8$ & 17 & 3 & 10 & 30 \\
\hline$S 9$ & 10 & 1 & 7 & 22 \\
\hline$S 10$ & 3 & 1 & 3 & 20 \\
\hline$S 11$ & 10 & 1 & 5 & 51 \\
\hline$S 12$ & 25 & 2 & 7 & 24 \\
\hline$S 13$ & 7 & 1 & 2 & 14 \\
\hline$S 14$ & 2 & 0 & 4 & 9 \\
\hline$S 15$ & 3 & 0 & 1 & 7 \\
\hline$S 16$ & 9 & 0 & 6 & 16 \\
\hline$S 17$ & 4 & 0 & 7 & 23 \\
\hline$S 18$ & 1 & 3 & 5 & 6 \\
\hline$S 19$ & 9 & 2 & 7 & 9 \\
\hline$S 20$ & 6 & 3 & 3 & 16 \\
\hline Total & 184 & 37 & 111 & 402 \\
\hline
\end{tabular}

As can be noticed in Table 4, the highest number of disfluency type was hesitations. To present it clearly, the researcher shows below in Figure (12) the percentage of disfluency types used by the EFL learners of this study.

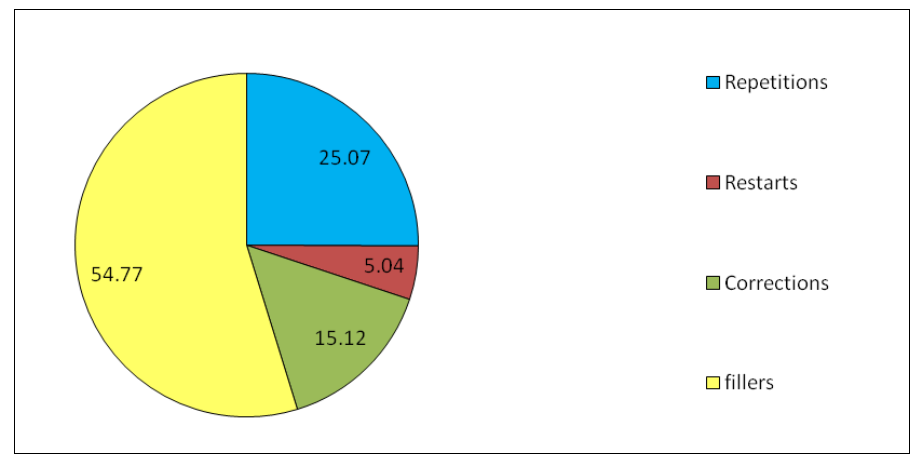

Figure 2. Percentage of Disfluency Types

As it can be seen in the above diagram, Figure 12, the EFL learners at Taiz University experienced the flowing sub-types of disfluencies as $54.77 \%$ hesitations (fillers), $25.07 \%$ repetitions, $15.12 \%$ corrections and $5.04 \%$ restarts. All of them are separately discussed in the coming paragraphs in some detail.

\subsection{Filled pauses}

The identification of filled pauses takes many forms in the literature; most researchers use the transcriptions such as $u h$ and um. Other researchers use transcriptions as $\mathrm{mm}$ or eh. However, transcribing a filler of $u m$ as $\mathrm{mm}$ would delete the vowel sound which is the nucleus of the syllable and therefore counted as a 
syllable in the calculations of the syllables of the sample. Therefore, the filler words of this study were transcribed in the form of ahs or ums; ers also were used, though rarely. To get an accurate count for the filler words in each utterance, the researcher underlined each filler word and then calculated both manually and using Word Processor (2007) to count underlined words of each sample separately. Those fillers manifest hesitations of the speakers and reflect the process of recalling a word or a structure. Chambers (1997) makes an interesting comparison between the reasons behind native and non-native use of hesitation markers. He argues that native speakers are more likely to hesitate "when expressing new thoughts as in a seminar than in a routine day to day exchange" ( p. 538). He goes further explaining that silent pauses in the middle of utterances indicate a search for an idea, or the best way to explain it or for the grammatical form in the case of language learners. He concludes the comparison by stating that the native speakers are unlikely to hesitate for monitoring accurate production while learners' hesitations mostly express learners' dependence on linguistic proficiency in monitoring production.

There are some words, other than um, ah or er, that do not carry a semantic meaning in themselves but are used by native and non-native speakers to fill time with speech. Those words are mostly regarded as a sign of speech processing or as discourse markers; such as you know, well, kind of. However, none of those filler words were used in all the speech samples collected in this study except for one speaker who used the filler word 'you know' only once (she um (483) you know um (1.928) [she] (357) ah (1.103) put herself). The point to mention here is that such filler words, though undesirable, are better than filling time with ums, ahs or ers. The other filler word was 'what' which is not common to non-native speakers, but perhaps a mother tongue influence as the filler word Aysh (meaning what) which is commonly used in the Taizi dialect when looking for a word or a term while speaking. That filler word was also used by only one speaker (S13) in two utterances only, (That means she (557) ah what [she] (869) she appears that she's innonce, but she is not). Therefore, what was counted as a filler word in those utterances. Alright was also used by one participant (S13) as a filler word and so was counted as a filler word.

\subsection{Number of Filled Pauses per minute}

Another aspect in the discussion of filled pauses is the number of filled pauses per minute. Figure 3 below shows the results of the calculations of filled pauses per minute. The average number of filled pauses per minute in the speech samples of the present study was 12.14 which is a big deal in comparison to the average number of filled pauses per minute in the speech samples of Kormos and Denes's (2004) study in which the advanced learners used an average of 8.28 filled pauses per minute while the low-intermediate learners used an average of 16.3 filled pauses per minute. The filler words are a reflection of hesitation, and they help the speaker to fill time with speech. However, the presence of fillers in the non-native speech is always regarded as a sign of disfluency. 


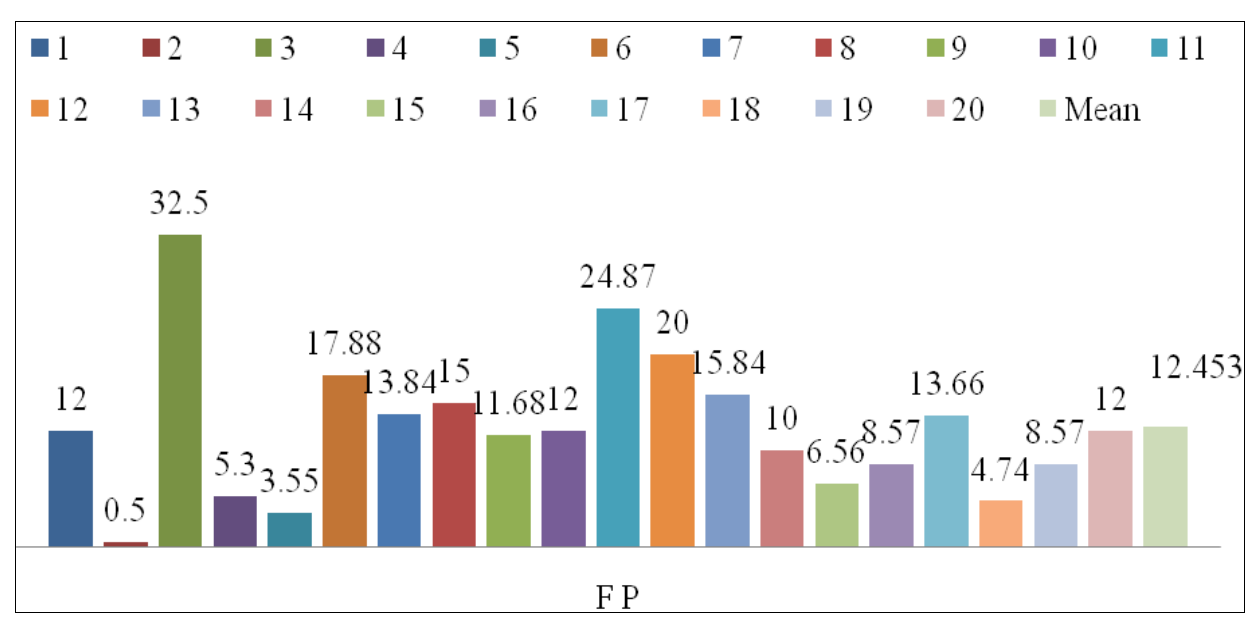

Figure 3. The Participants' Filled Pauses Per Minute

Overusing fillers while speaking can be regarded as a sign that the planning efforts are higher. Such use of filled pauses is sometimes regarded as a negative technique and a sign of encoding difficulties (Kormos 2006). The EFL learners at Taiz University showed an over use of the fillers 'ah' and ' $u m$ ' in different parts of their utterances. Fillers were noted to occur in between the subject and the complement, the subject and the verb, or between repetitions and corrections. More examples of fillers of the sample of this study are given here:

\section{Examples: Filler words between the subject and the complement:}

(S1) [one man] is ah walking in the street

(S13) there is ah a shock

(S7) there is ah a noble man sitting next to her.

\section{Examples: Filler words between the subject and the verb:}

(S13) she ah open her ah bag

(S15) she ah (564) steal (891) his bag

(S16) the man ah say 'Good Bye'

\section{Examples: Filler words at the clause boundary:}

(S17) After that (520) um (938) she was waiting what happened (304).

(S9) Ah this story about a girl (555) ah

(S6) But, ah it's really so bad.

(S17) Then, ah [the] at the end of the story,

\section{Examples: Filler words between the verb and the object:}

(S17) Ah and um (1.493) she just (1.827) looked at ah his wallet (668)

(S18) A man was sitting besides her reading (616) um a book.

(S18) How could she just give him (319) ah such a return!

(S1) I talk about(482) ah a story 


\section{Examples: Filler words before repetitions:}

(S14) So she is (809) um (371) [she is] a thief

(S6) She get her phone out (475) and ah she ah [she] was ah (624) ah [she was] reading something

(S6) It is really something that is so bad in our ah (713) [in our] society.

(S19) There ah [there] is woman and man

\section{Examples: Filler words before corrections:}

(S4) She gave it ah [he gave it] to the lady

(S3) There is ah [a m] ah a woman (757)

(S11) she (304) um leave (1.017) the ah [his] ah her place (378) ah in um

(2.020) in [t] ah track

(S17) [She] ah he [gived] (631) he gave

\subsection{Repetitions}

The second most frequent disfluency marker in the speeches produced by the EFL learners at Taiz University was repetition. The learners repeated syllables, words, phrases and sometimes whole sentences. The repetition phenomenon reveals that the speakers are not fluent. Kormos (2006) claims that repetitions, reformulations, and restarts which often accompany silent or filled pauses are signs of encoding difficulties during the speech production process. Words repetition meant for emphasis were not included in the calculation of the repeated words, and they occurred very rarely. To cite an example, in this utterance by Speaker (16) "I think the man who are kind (1.173) on this life (1.017) always always he is (408) a victim", the word always was used for emphasis and therefore it was not counted as an example of repetition. Given below are some examples of repetitions taken from the transcripts of the present study:

\section{Examples: Repetition of parts of the words:}

(S11) [repre] (854) represent

(S12) [his] (518) [wa] ah wallet too

(S3) [far] ah farewell

(S10) she's [a th] a thief too

\section{Examples: Repetition of one word:}

(S 14) I think she (349) [she] couldn't ah take the money

(S6) and get her [her] bag out

(S16) come to him hanging [hanging] him

\section{Examples: Repetition of two or more words:}

(S16) They are (490) just [they are] friends

(S6) sitting next to [next to] a man

(S3) when she was ah [when she] [when she was] 


\section{Examples: Repetition of a sentence:}

(S8) There is a girl. (728) [There is a girl]

(S3) that ah there is ah [a m] ah a woman (757) ah [tha] [that there is a woman]

(S2) When the train (1.057) arrived, (943) [when the train arrived]

\subsection{Corrections}

According to Mirzaei and Heidari (2013), "Self-repairs can be prompted by three different circumstances: a lapse in the encoding process, the generation of an inappropriate or inadequate message, and incomplete knowledge of L2 system" (p.51). In this study, self-corrections were marked where speakers make a change to their message such as choosing different vocabulary, sentence structure, tense, pronoun, conjunction or different preposition. In these examples, Speaker 1 and Speaker 14 changed the tense from present to past, while Speaker 9 changed the sentence structure deleting the auxiliary verb was, then she added the present simple marker to the verb get.

(S1) [I see] (319) I saw

(S14) She looks very [she looked very] sad

(S9) ... she was [ge] er [she get] (709) she gets nervous

The following diagram shows the types of corrections found in the speech sample of the present study in percentage.

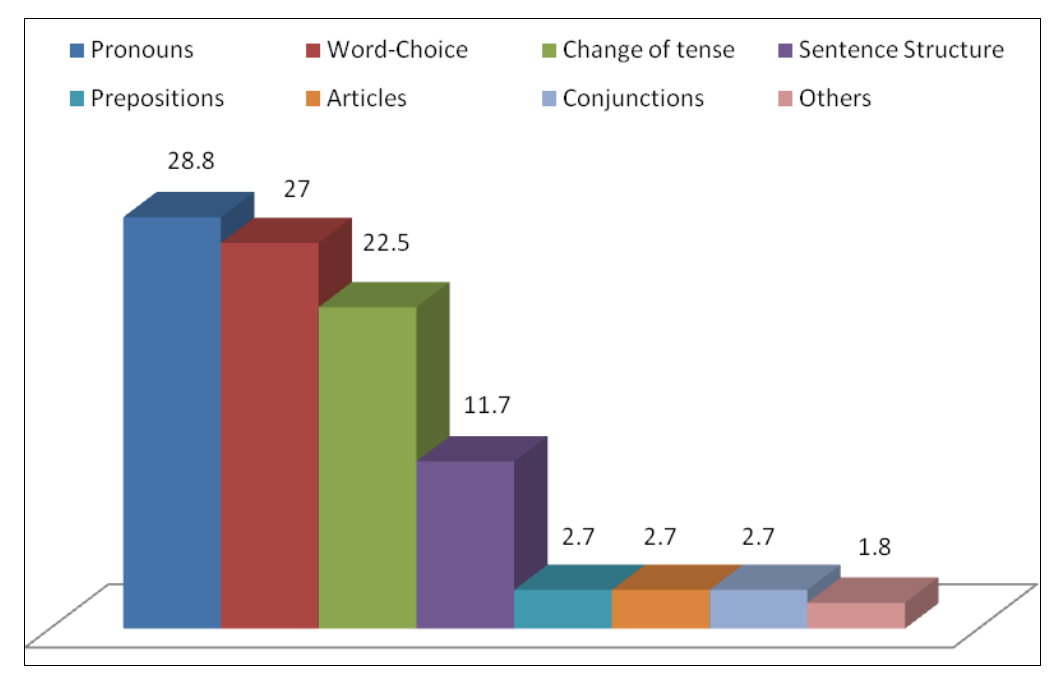

Figure 4. Percentage of Self-correction Types

As can be seen from Figure 14 above, the corrections in the speech sample collected in this study involved changes of tense $22.5 \%$, word-choice $27.0 \%$, pronouns $28.8 \%$, sentence structure $11.7 \%$, prepositions $2.7 \%$, articles $2.7 \%$, and conjunctions $2.7 \%$. The highest aspect of self-corrections was the change of the pronouns.

\subsection{Restarts}

Restarts, sometimes referred to as false starts, are defined by Riggenbach (1991, p. 427) as "reformulations in which the original utterance is rejected". That is, after the speaker begins an utterance, he or she stops the attempted utterance and 
begins a new utterance. Restarts differ from self-corrections in the sense that in restarts, the first attempt is rejected before it is finished and the second attempt does not necessarily involve corrections. The restarts were the least type of disfluencies noticed in the present study with a percentage of $5.04 \%$ of the total number of disfluencies. Here is an example in which Speaker 4 made a restart

(S4) [He'll] ah (490) he say to her.

Here, Speaker 4 started a sentence using the modal verb will, and then she restarted the sentence using the verb say instead of the modal will, and she discarded the previous message. In a restart, the change made by the speaker is not necessarily to make the sentence more grammatical, the speaker changes the whole message.

Here are some more examples of restarts:

\section{Examples: Restarts}

(S6) [took the ba] ah ran after the [ma] the thief

(S7) [shee] (542) [we find]

(S9) [bec] ah to show that

(S 20) [For exa] stoling off any things (408).

(S19) [Some] Then, suddenly, one person came and

\section{Conclusion}

The findings of the present study showed that the speech by EFL learners at Taiz University is filled with hesitations represented by the non-verbal words 'ah' 'um' and 'er' along with much restarts and self-corrections. Beside their use of filled and silent pauses, the EFL learners at Taiz University also used repetitions of a word or parts of a word, sometimes of a whole phrase, in order to gain time to produce what they intend to say. It is recommended that learners should be given an opportunity to develop accuracy as well as fluency and not neglecting any of them. Besides, they should be introduced to the types of disfluencies and to the non-fluent pausing in order to avoid using them in speech. Teachers also need to make their learners aware of the roles of the temporal features of disfluency and how such features affect the listeners' perceptions. That is, the EFL learners need to better understand that speaking an L2 appropriately is not only by mastering its grammatical features, but also by taking into their consideration the temporal aspects of speaking.

\section{References}

Alanisi, M. (2012). Developing Yemeni student-teachers' proficiency in speaking English at the university level. (Doctoral Dissertation). EFL University, Hyderabad, India.

Al-Ghazali, A., \& Alrefaee, Y. (2019). Silent Pauses in the Speech of Yemeni EFL Learners. ELS Journal on Interdisciplinary Studies in Humanities, 2 (1), 39-48. doi: http://dx.doi.org/10.34050/els-jish.v2i1.6142. 
Alyan, A. (2013). Oral communication problems encountering English major students: Perspectives of learners and teachers in Palestinian EFL university context. The Islamic University of Gaza Palestine. Arab World English Journal. International peer reviewed journal.(4) Pp. 226-238. Retrieved from: (www.awej.org).

Bosker, $\mathrm{H}$. (2014). The processing and evaluation of fluency in native and non-native speech. University of Nijmegen, The Netherlands: Max Planck Institute for Psycholinguistics.

Bulc, T.; Hadzi, V. \& Horga, D. (2010). Speech fluency, a result of oral language proficiency? University of Ljubljana. 87-100

Chambers, F. 1997. 'What do we mean by fluency?'. System, 25:4. 535-544

Chon, C., Sawyer, J.,\& Ambrose, N. (2007). Measuring speech rates in fluent and disfluent utterances. University of Illinois at Urbana-Champaign.

Gósy, Mária. 2007. "Disfluencies and Self-monitoring". Govor, 26: 91-110.

Hemerka, V. 2009. Low speaking performance in learners of English. Bachelor Thesis. Masaryk University. Faculty of Education. Department of English Language and Literature.

Kormos, J. \& Dénes, M. (2004). Exploring measures and perceptions of fluency in the speech of second language learners. An International Journal of Educational Technology and Applied Linguistics. Eötvös Loránd University, Budapest System (32). 145-164

Kormos, J. (2006). Speech production and second language acquisition. Mahwah, New Jersey: Lawrence Erlbaum.

Lennon, P. 1990. Investigating fluency in EFL: a quantitative approach. Language Learning, (40): 387-417

Mirzaei, A. \& Heidari, N. (2013). Researching (non) fluent L2 speakers' oral communication deficiencies: A psycholinguistic perspective. The Journal of Teaching Language Skills (JTLS). (5) 45-70

Mohanraj, S. (2006). Course descriptions in English. Department of English, Faculty of Education, Taiz University.

Nunan, D. 2003. Practical English language teaching. NY:McGraw-Hill. In Febriyanti, E. (n. d.).Teaching speaking of English as a foreign language: Problems and solutions. Dosen Pendidikan Bahasa Inggris, FKIP Universitas Lambung. Mangkurat.

Richards, J. C. \& Schmidt, A. R. (2002). The dictionary of language teaching and applied linguistics. (3rd Ed.). London: Pearsn Education Limited.

Riggenbach, H. (1991). Toward an understanding of fluency: A microanalysis of nonnative speaker conversations. Discourse Processes, 14, 423-441.

Schmidt, R. (1992). Psychological mechanisms underlying second language fluency. Studies in Second Language Acquisition. (14). 357-385.

Segalowitz, N. (2010). Cognitive bases of second language fluency. New York: Routledge. 